Article

\title{
Integrating a Hybrid Back Propagation Neural Network and Particle Swarm Optimization for Estimating Soil Heavy Metal Contents Using Hyperspectral Data
}

\author{
Piao Liu ${ }^{1}$, Zhenhua Liu ${ }^{1,2, *}$, Yueming Hu ${ }^{1,2, *}$, Zhou Shi ${ }^{3}{ }^{\circledR}$, Yuchun Pan ${ }^{4}$, Lu Wang ${ }^{1,2}$ and \\ Guangxing Wang 1,5 (i) \\ 1 College of Natural Resources and Environment, South China Agricultural University, Guangzhou 510642, \\ China; liupiao@stu.scau.edu.cn (P.L.); selinapple@scau.edu.cn (L.W.); gxwang@siu.edu (G.W.) \\ 2 Guangdong Provincial Key Laboratory of Land Use and Consolidation, Guangzhou 510642, China \\ 3 Institute of Agricultural Remote Sensing and Information Technology Application, Zhejiang University, \\ Hangzhou 310058, China; shizhou@zju.edu.cn \\ 4 National Engineering Research Center for Information Technology in Agriculture, Beijing 100089, China; \\ chewh@163.com \\ 5 Department of Geography and Environmental Resources, Southern Illinois University, Carbondale, \\ IL 62901, USA \\ * Correspondence: zhenhua@scau.edu.cn (Z.L.); ymhu@scau.edu.cn (Y.H.)
}

Received: 5 November 2018; Accepted: 11 January 2019; Published: 15 January 2019

\begin{abstract}
Soil heavy metals affect human life and the environment, and thus, it is very necessary to monitor their contents. Substantial research has been conducted to estimate and map soil heavy metals in large areas using hyperspectral data and machine learning methods (such as neural network), however, lower estimation accuracy is often obtained. In order to improve the estimation accuracy, in this study, a back propagation neural network (BPNN) was combined with the particle swarm optimization (PSO), which led to an integrated PSO-BPNN method used to estimate the contents of soil heavy metals: $\mathrm{Cd}, \mathrm{Hg}$, and As. This study was conducted in Guangdong, China, based on the soil heavy metal contents and hyperspectral data collected from 90 soil samples. The prediction accuracies from BPNN and PSO-BPNN were compared using field observations. The results showed that, 1 ) the sample averages of Cd, $\mathrm{Hg}$, and As were $0.174 \mathrm{mg} / \mathrm{kg}, 0.132 \mathrm{mg} / \mathrm{kg}$, and $9.761 \mathrm{mg} / \mathrm{kg}$, respectively, with the corresponding maximum values of $0.570 \mathrm{mg} / \mathrm{kg}, 0.310 \mathrm{mg} / \mathrm{kg}$, and $68.600 \mathrm{mg} / \mathrm{kg}$ being higher than the environment baseline values; 2 ) the transformed and combined spectral variables had higher correlations with the contents of the soil heavy metals than the original spectral data; 3) PSO-BPNN significantly improved the estimation accuracy of the soil heavy metal contents, with the decrease in the mean relative error (MRE) and relative root mean square error (RRMSE) by $68 \%$ to $71 \%$, and $64 \%$ to $67 \%$, respectively. This indicated that the PSO-BPNN provided great potential to estimate the soil heavy metal contents; and 4) with the PSO-BPNN, the Cd content could also be mapped using Huanjing-1A Hyperspectral Imager (HSI) data with a RRMSE value of 36\%, implying that the PSO-BPNN method could be utilized to map the heavy metal content in soil, using both field spectral data and hyperspectral imagery for the large area.
\end{abstract}

Keywords: heavy metal; PSO-BPNN Method, soil sample; HJ-1A Hyper Spectral Imager; Guangdong

\section{Introduction}

With the fast increase of industrial and chemical pesticide pollutants, many heavy metals enter the soil in many ways, which induces direct or indirect harms to the environment and humanity. 
Estimating soil heavy metal contents is necessary for monitoring the health of soil and for taking preventative measures to avoid contamination.

The conventional method of estimating soil heavy metal contents is based on regular field samples and subsequent chemical analysis of the sampled soils in a laboratory, followed by spatial interpolation to acquire regional-scale maps of soil heavy metal contents. This is time-consuming and costly with low estimation accuracy at local areas [1,2]. Remote sensing technologies could lead to spatially explicit estimates of various soil properties and monitor their dynamics at a regional scale, with low cost and substantial research having been conducted in this field, especially for mining areas. For example, Tan et al. (2014) used hyperspectral images to quantitatively estimate the contents of $\mathrm{As}, \mathrm{Zn}, \mathrm{Cu}, \mathrm{Cr}$, and $\mathrm{Pb}$ in a reclaimed farmland [3]. Wu et al. (2009) studied mid-infrared diffuse reflectance spectroscopy to accurately estimate heavy metal contents in soils for the mining areas located in Jiangning District and Baguazhou District [4]. Kooistra et al. (2003) found that the soil spectral reflectance could be utilized to acquire the pollution levels of $\mathrm{Zn}$ and $\mathrm{Cd}$ in soils [5].

Various studies using hyperspectral techniques to map heavy metal contents have been reported. These studies are based on the relationships of soil heavy metals with soil hyperspectral data that have been developed using statistical regression analysis, including multiple linear regression $[3,6]$, multiple stepwise regression analysis [7], principal component regression [8,9], and partial least-squares regression analysis $[3,5,10]$. The relationships often lead to ideal estimation accuracy for some specific research areas. However, when the relationships are applied to other areas, low estimation accuracies are usually obtained.

Various machine learning algorithms have been used to improve the estimation of soil heavy metal contents. Ghadimi (2015) used an artificial neural network algorithm (ANN) to predict the contents of soil heavy metals: $\mathrm{Pb}, \mathrm{Zn}$, and $\mathrm{Cu}$ [11]. Gandhimathi and Meenambal (2012) also employed the ANN and hyperspectral data to estimate the contents of soil heavy metals: $\mathrm{Cr}, \mathrm{Pb}$, and As [12]. The reports showed that it is difficult to obtain a high estimation accuracy using the ANN, due to large errors of initial parameters. Other studies showed that support vector machine (SVM) regression could lead to higher estimation accuracies of soil heavy metal Fe content than the ANN [13]. Its insensitivity for the selection of kernel functions is limited by small samples, which may affect the estimation accuracy for soil heavy metal contents in large areas.

The main objective of this study was to determine a method to accurately estimate soil heavy metal contents for large areas using hyperspectral data by optimizing the weights and threshold of the network. The back propagation neural network (BPNN) was combined with the particle swarm optimization (PSO), which led to an integrated PSO-BPNN method. The method was examined in Guangdong province in order to circumvent the lower estimation accuracy using the BPNN algorithm and the small sample problem existing in the SVM Regression.

\section{Materials and Methods}

\subsection{Study Site and Data}

The study area is located in Guangdong Province of Southern China (Figure 1) and has a humid sub-tropical monsoon climate characterized by warm winters, hot summers, little frost or snow, sufficient precipitation, and sunshine. This study area has an annual average temperature of $19^{\circ} \mathrm{C}-24^{\circ} \mathrm{C}$ and a mean annual rainfall of $1300 \mathrm{~mm}-2500 \mathrm{~mm}$. Guangdong has become a commercially developed area with abundant non-ferrous metals and rare metal resources. Heavy metal pollution in the soils has become a serious problem, due to the quick economic development. The contaminated soil reached $40 \%$ in the Pearl River Delta of Guangdong Province [14].

In this study, two datasets were collected from a total of 90 sample points. At each sample point, a soil sample of the top $0-20 \mathrm{~cm}$ depth was obtained to determine the contents of soil heavy metals: $\mathrm{Cd}, \mathrm{Hg}$ and As, and hyperspectral reflectance data. The sample points were located using a global positioning system (GPS). The first dataset was composed of the data from 75 soil samples 
and collected during 22-24 June 2015, and out of which the data from 50 soil samples (black dots in Figure 1) were used to train the methods, and to establish the relationships between spectral variables and corresponding soil heavy metal contents. The data from the left 20 soil samples (red points in Figure 1) were used to assess the accuracy of the estimated soil heavy metal values. The second dataset consisted of the data collected from 15 sample points coinciding with the overpass time of HJ-1A satellite (30 October 2017) and was thus utilized to assess the feasibility of the developed model for the satellite data. The soil samples were air-dried at room temperature for three days to standardize the moisture level, and the small stones and plant residues were removed. The total of 90 soil samples were ground in an agate mortar. The ground soil samples were passed through a 20-mesh sieve $(0.84 \mathrm{~mm})$ in order to minimize the impact of particle size on soil spectral reflectance $[15,16]$.

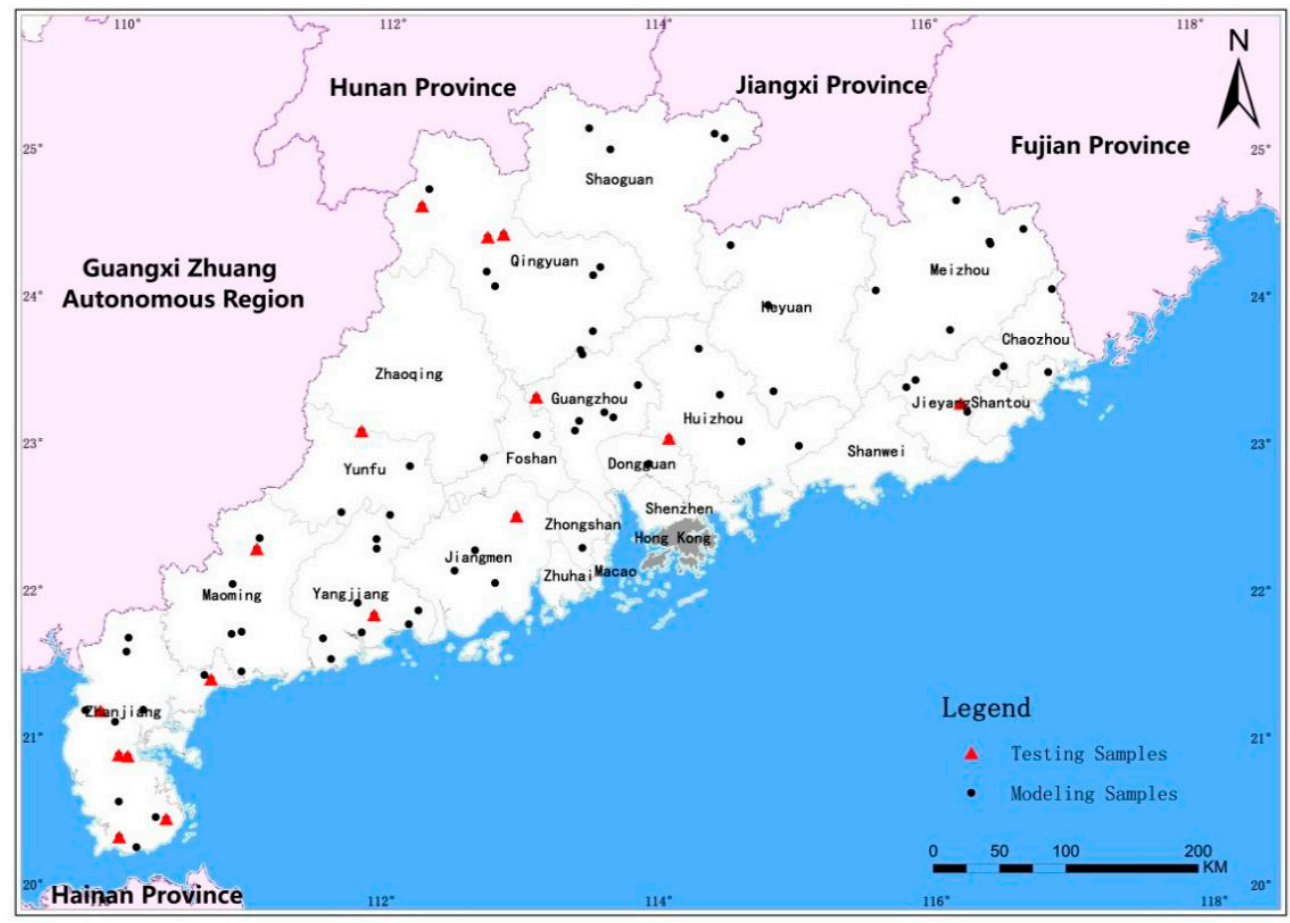

Figure 1. The study area and the distribution of soil sample points (black dots and red triangles represented training and test samples, respectively).

\subsection{Experimental Data Pre-Processing}

\subsubsection{Chemical Analysis of Soil Properties}

Prior to measuring the contents of the soil heavy metals, the soil samples were digested by hydrofluoric acid (HF)-nitric acid $\left(\mathrm{HNO}_{3}\right)$-perchloric acid $\left(\mathrm{HCLO}_{4}\right)$ to determine the total contents of the three elements [17]. The digested soil samples were processed through an atomic fluorescence spectrometer to determine the $\mathrm{Hg}$ and As contents. The flame atomic absorption spectrometry (FAAS) was used to acquire the $\mathrm{Cd}$ content [4].

\subsubsection{Spectral Measurements and Pre-Processing of Soil Samples}

An AvaField portable spectrometer (Avantes, Inc., Holland) with a 340- $2511 \mathrm{~nm}$ spectrum was used to collect the spectral reflectance data of soil samples in a laboratory. The spectral sampling interval was $0.6 \mathrm{~nm}$. The entire spectrometric experiment was performed in a black box. Each treated sample was placed in a black paper cup with a diameter of $10 \mathrm{~cm}$ and a depth greater than $5 \mathrm{~cm}$. A $50 \mathrm{~W}$ halogen lamp was used to estimate sunlight with a $10^{\circ}$ field of view (FOV). The soil sample was subjected to soil reflection spectroscopy that is perpendicular to the soil sample. A white plate was used for calibration prior to collection in order to obtain the absolute reflectance. To mitigate the 
impact of instrument noise, the values of spectral bands ( $340.316-2511.179 \mathrm{~nm}$ ) were initially smoothed using a Savitzky-Golay filter to obtain the stable spectrum curves. This method reduces the impact of glitch noise and purifies spectral information [18,19]. In order to obtain the spectral characteristics of the interest targets, the smoothed spectral data were transformed using the continuum removal (CR), the first derivative (FD), the second derivative (SD), the reciprocal transformation (RT), and the logarithm of reciprocal (LG), which could eliminate or reduce the effect of the background noise and the change in signal intensity caused by the soil surface spectral scattering and absorption. These transformation spectral data were used to build a mapping method with the soil heavy metals.

\subsection{Image Acquisition and Preprocessing}

In order to extend the application of the established model to hyperspectral satellite data, a HJ-1A satellite image (Path 457/Row 88, Scene PathBias A/ Scene RowBias 2) was acquired to retrieve the spatial distribution of soil heavy metal contents. The image was dated on 30 October 2017 and covered a part of Guangzhou, Guangdong province, China $\left(23.53-23.77^{\circ} \mathrm{N}\right.$ and $\left.113.2-113.48^{\circ} \mathrm{E}\right)$ (Figure 2). It has a spatial resolution of $100 \mathrm{~m}$, with a swath width of $50 \mathrm{~km}$ with a wavelength range of $459 \mathrm{~nm}-956 \mathrm{~nm}$, a total of 115 bands, and a spectral interval of $5 \mathrm{~nm}$. Although there was a narrower spectral range as compared with NASA's widely used Earth Observing MODIS and EO-1 Hyperion, the HJ-1A HSI imaging spectrometer improved the spectral resolution for ground feature identification and information extraction [20].

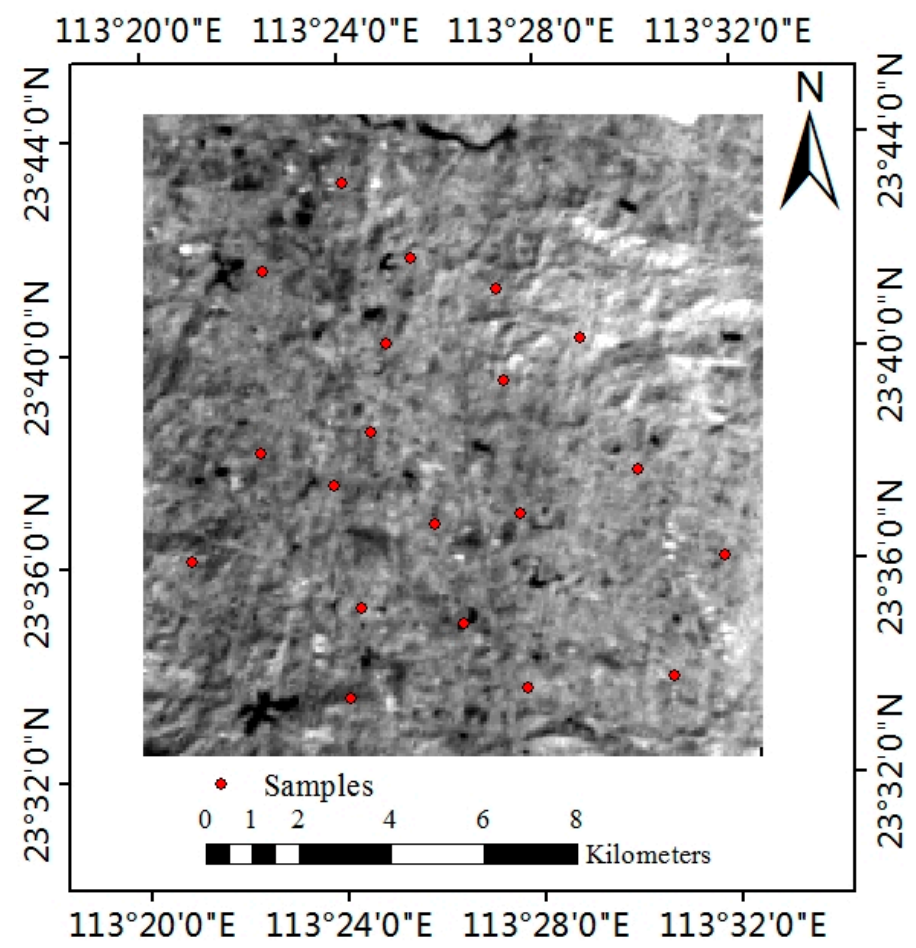

Figure 2. The area covered by the HJ-1A image and the locations of the soil samples (red dots).

To improve the relationships of spectral variables with the soil heavy metal contents in the study, the image enhancements, including stripe noise reduction, radiometric calibration, geometric rectification, and atmospheric correction were conducted. In this study, the moment matching method was applied to remove the stripe noise. The fast line-of-sight atmospheric analysis of spectral hyper-cubes (FLAASH) module in the environment for visualizing images (ENVI) system was used to perform atmospheric/radiometric correction for the HJ-1A satellite image. Geometric precision correction for HJ-1A HSI data was conducted using a quadratic polynomial model and the cubic convolution interpolation method, and the geometric correction errors were controlled within 0.5 pixels [21]. 


\subsection{Selection of Optimum Spectral Variables}

In this study, the Pearson product moment correlation was used to determinate the spectral variables that had the highest correlations with the contents of the soil heavy metals $(\mathrm{Cd}, \mathrm{Hg}$, and As). In order to eliminate the collinearity of the spectral variables, the variance inflation factor (VIF) was used [22] with the rules: $0<\mathrm{VIF}<10,10 \leq \mathrm{VIF}<100$ and VIF $\geq 100$ indicating that no, strong, or severe multi-collinearity existed, respectively. According to the rules, the optimal spectral variables were selected and utilized as the input data of the network.

\subsection{The BPNN Method to Estimate Soil Heavy Metal Contents}

The BPNN is a parallel information processing method, able to work out complex, non-linear relationships by a learning model and by using experimental data [23]. The BPNN method has been widely used for prediction, data classification, characteristic recognition, and non-linear function approximation. The BPNN was used to estimate the heavy metal contents in the soil using a visible and near-infrared (VNIR) reflectance data. The topological structure of BPNN consisted of an input layer, a hidden layer, and an output layer. The input layer was composed of three or four nodes that represented the selected spectral variables that were used to estimate the response and the output layer consisted of one node, which represented the constituents of the heavy metals in the soils: Cd, As, and $\mathrm{Hg}$. The number of nodes in the hidden layer was determined by a complex relationship between the transformed spectral variables and the soil heavy metal contents, which was a crucial parameter of BPNN. The BPNN is primarily divided into two processes during the training of experimental data: Forward propagation and error back propagation [24].

(1) Forward propagation: In neural networks, the neurons are linked between the current layer and the next one, but this connection is not within the same layer. Once a set of spectral variables were presented to the network, the input values were transmitted through the links to the hidden layer. Therefore, the equation of the output value was expressed as [24]:

$$
H_{J}=f\left(\sum_{i=1}^{n} w_{i j} x_{i}-a_{i j}\right) \quad j=1,2, \ldots, l
$$

where $H_{J}$ indicates the output values in the $j$ th hidden node, $w_{i j}$ represents the weights between the $i$ th input node, and the $j$ th hidden node, $a_{j}$ denotes the threshold value between the $i$ th input node and $j$ th hidden node, $n$ is the number of spectral variables, and $x_{i}$ is the spectral value in band $i$.

The output value $(\mathrm{H})$ in the hidden layer was transmitted to the output layer, and the equation of the output value was expressed as [24]:

$$
O_{k}=\sum_{j=1}^{l} H_{j} w_{j k}-b_{j k} \quad k=1,2, \ldots, m
$$

where $O_{k}$ is the output values in the $k$ th output node, $w_{j k}$ represents the weights between the $j$ th hidden node, the $k$ th output node, $b_{j k}$ denotes the threshold value between the $j$ th hidden node and the $k$ th output node, and $l$ was the number of hidden nodes.

(2) Error back propagation: The output from the above forward propagation was compared with the real value to obtain an error. The error was propagated back to the network to improve the weights. This process was repeated until the error reached a specified threshold value. The equation of the error value was expressed as [24]:

$$
e_{k}=\frac{1}{2} \sum_{j=1}^{m}\left(Y_{k}-O_{k}\right)^{2} k=1,2, \ldots, m
$$

where $e_{k}$ represents the error between the output value in the $k$ th output node and the real value of a soil heavy metal content, $Y_{k}$ is the real value of a soil heavy metal content, and $O_{k}$ is the output value in the $k$ th output node. 


\subsection{The PSO-BPNN Method to Estimate Soil Heavy Metal Contents}

The particle swarm optimization (PSO) was initially introduced by Eberhart and Kennedy (1995) in order to solve the problems with continuous search space [25]. The PSO-BPNN combined the PSO algorithm's global optimization ability and the BPNN algorithm's local search advantage, which circumvented the slow convergence problem and avoided becoming trapped in a local minimum. The reaching process of BPNN is trained by the PSO algorithm, which has the position of each particle in the swarm that was represented as the weights and the thresholds of nodes in the BPNN. The network error between the actual value of a soil heavy metal content and the estimated value in the output layer was defined as the fitness function in the training. Each particle represented a candidate solution to minimize the network error. The optimum weights and thresholds were presented to determine the minimum network error. In the training experimental data process of PSO-BPNN, the spectral variables were selected as inputs of the networks and the outputs of networks were the heavy metal contents, including $\mathrm{Hg}$, As, and Cd. The PSO algorithm that was used to train the BPNN's weights and the threshold process is shown in Figure 3.

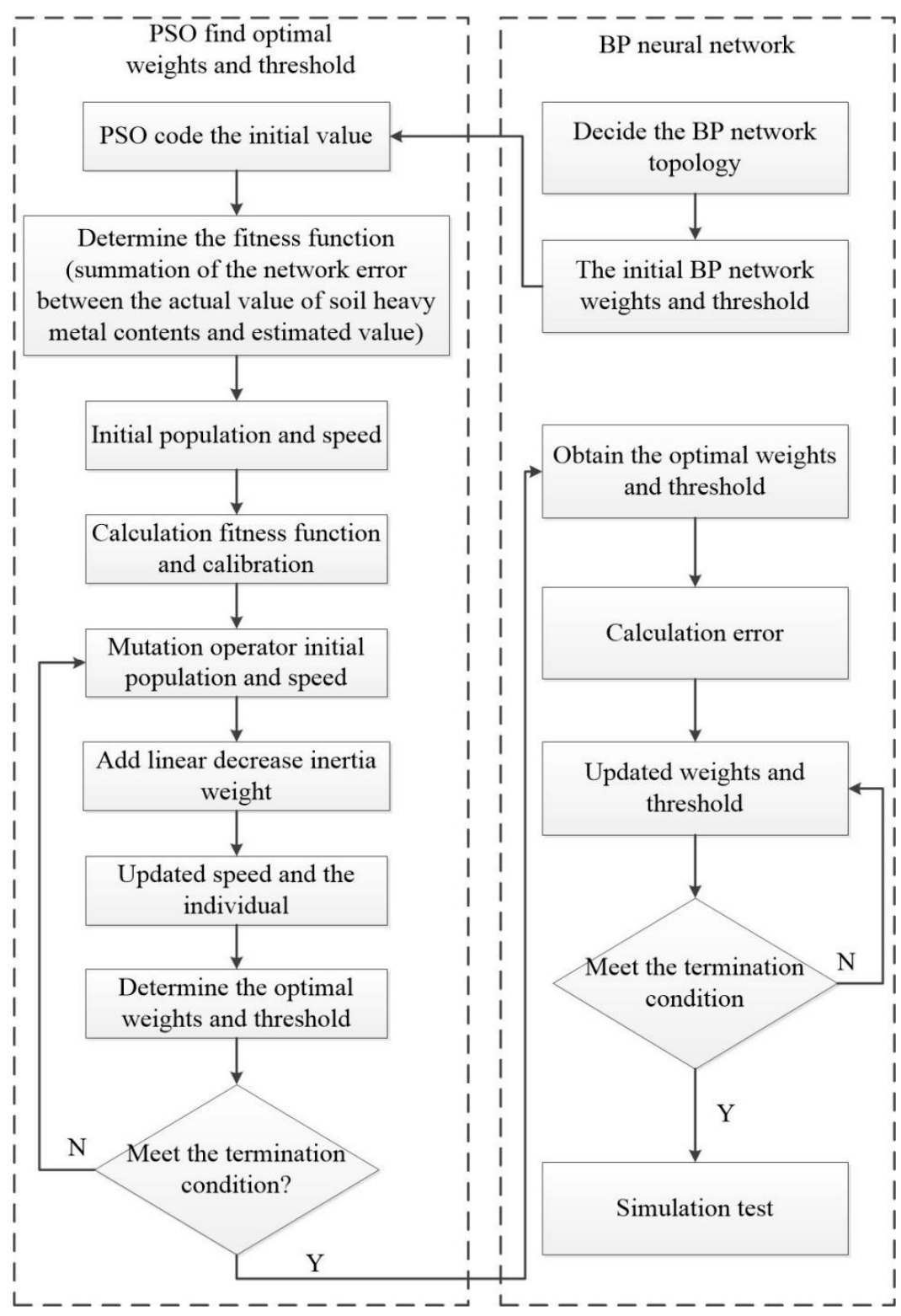

Figure 3. The flow chart of the particle swarm optimization (PSO) algorithm used to optimize the back propagation neural network (BPNN) weights and the threshold. 


\section{Results}

\subsection{Descriptive Statistics of Soil Properties in the Study Area}

The statistics of the data for the heavy metals measured from the 75 soil samples is calculated in Table 1. The average values of $\mathrm{Cd}, \mathrm{Hg}$, and As contents were lower than the normative heavy metal contents, while their maximum values were much higher than the environment baseline values. The statistic results implied that the spatial distributions of three soil heavy metal contents were heterogenic in the study area.

Table 1. Statistical values for the measured contents of soil heavy metals of the study area.

\begin{tabular}{cccccccc}
\hline Metal (mg/kg) & Minimum & Maximum & Mean & SD & CV (\%) & Background Value & Standard \\
\hline Cd & 0.003 & 0.570 & 0.174 & 0.111 & 63.79 & 0.034 & 0.3 \\
Hg & 0.026 & 0.310 & 0.132 & 0.085 & 64.44 & 0.078 & 0.3 \\
As & 1.370 & 68.600 & 9.761 & 7.487 & 76.70 & 10.50 & 30 \\
\hline
\end{tabular}

\subsection{Smoothing Spectral Data of Soil Heavy Metal Contents}

When the spectral reflectance of the soil samples was measured, each soil sample was scanned at different positions three times, and five spectral curves were collected for each position in order to eliminate the instability of the measurements. The average value was obtained for each soil sample and smoothed using a Savitzky-Golay filter (Figure 4). The trend changes of the spectral reflectance curves of 75 soil samples were similar. Overall, the spectral reflectance values increased rapidly with the increased wavelength. The great changes occurred at the spectral interval ( $400 \mathrm{~nm}-600 \mathrm{~nm}), \mathrm{due}$ to the spectral absorptions from the iron in the soil. The spectral reflectance values at the near-infrared spectral bands had small rates of changes but were higher than those in the visible spectral bands.

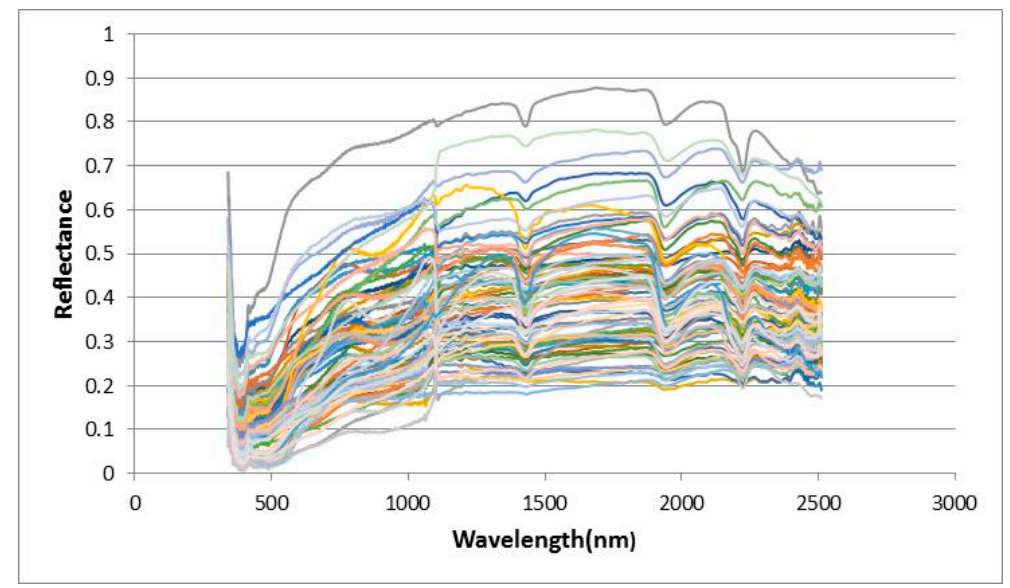

Figure 4. The curves of the soil spectral reflectance values.

\subsection{Optimal Spectral Variables for Retrieving Soil Heavy Metal Contents}

The correlation coefficients between the soil heavy metal $(\mathrm{Cd}, \mathrm{Hg}$, and As) contents and the spectral variables, including raw spectral data and transformed spectral variables, are shown in Figure 5. The correlation analysis revealed that the spectral transformations further highlighted the relationships of the reflectance characteristics with the soil heavy metal contents, which are hidden in the soil spectra, when compared with the raw reflectance bands. The first derivative spectral data had higher correlations with the contents of the three soil heavy metals than the other spectral transformations. Nevertheless, it was difficult to accurately model the relationships of the spectral characteristic with the soil heavy metal contents when the correlation coefficients were smaller than 0.4 . 


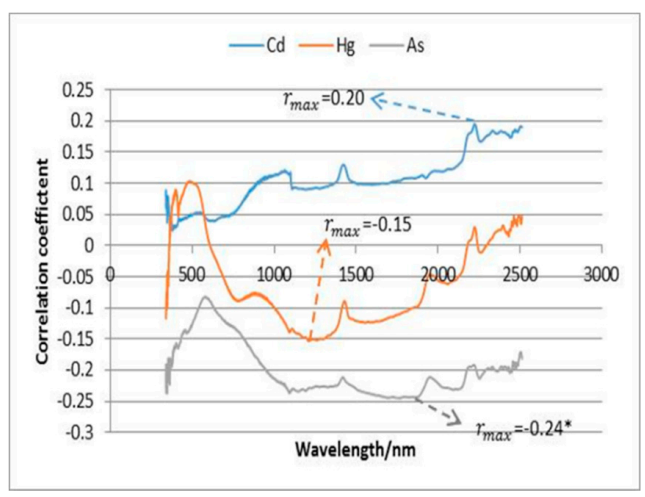

(a). Raw spectral bands

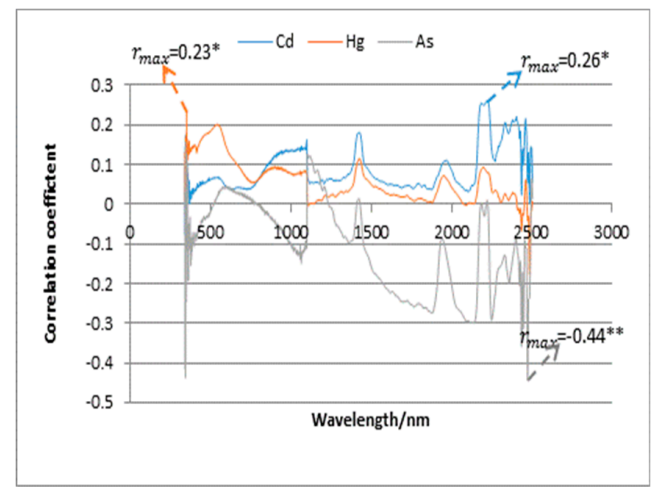

(b). Spectral variables after continuum removal (CR)

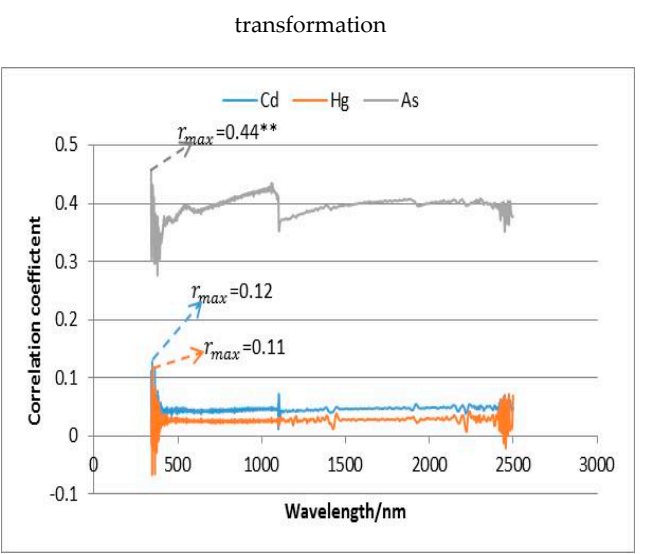

(d). Spectral variables after second derivative (SD)

transformation

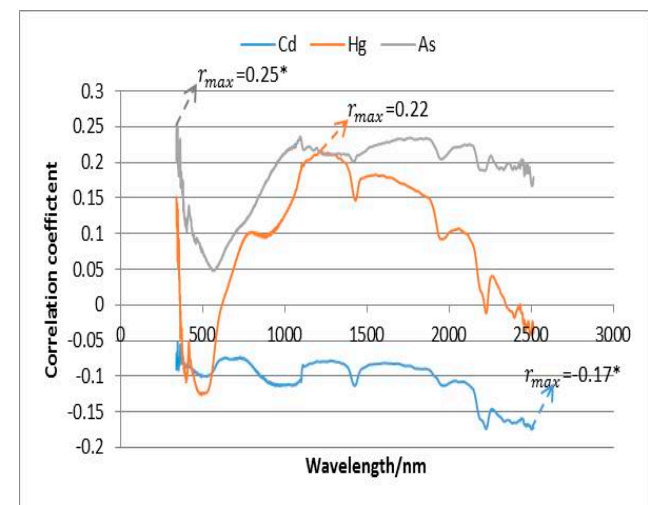

(f). Spectral variables after logarithm of reciprocal (LG)

(e). Spectral variables after reciprocal transformation (RT)

transformation

Figure 5. The correlation coefficients between the $\mathrm{Cd}, \mathrm{Hg}$, and $\mathrm{As}$ concentrations and the various spectral variables: (a) Raw spectral bands; (b) Spectral variables after CR transformation; (c) Spectral variables after FD transformation; (d) Spectral variables after SD transformation; (e) Spectral variables after RT transformation; and (f) Spectral variables after LG transformation ( $\mathrm{r}_{\max }$ is the highest correlation coefficient between the soil heavy metal contents and the spectral variables; ${ }^{*}$ and ${ }^{* *}$ mean that correlation was significant at the 0.05 and 0.01 level, respectively). 
In order to improve the estimation accuracies of the soil heavy metal contents, we further used the spectral variables with the maximum correlation coefficients to develop new spectral variables. That is, the combinations of spectral variables by the calculations of addition, subtraction, multiplication, and division operations. Table 2 shows the combined spectral variables that had the highest correlations with the soil heavy metal $(\mathrm{Cd}, \mathrm{Hg}$, and As) contents, which suggested that the combined spectral variables greatly improved the correlations with a range of the coefficients from 0.36 to 0.60 , being significant at the significant level of 0.01 .

To eliminate the multicollinearity among the combined spectral variables, the VIF analysis was performed in Table 3. The combined spectral variables were selected according to the following criteria: The greatest value of adjusted coefficient $\left(R^{2}\right)$ of determination; the statistically significant P-value of the partial F-test; and the VIF value of less than 10. The selected combinations of the spectral variables reduced the duplication of information and provided the potential of effectively accounting for the spatial variability of the soil heavy metal contents. They were considered to be optimal.

Table 2. The greatest correlation coefficients between the soil heavy metal contents and the combined spectral variables (* and ** mean that the correlation was significant at the 0.05 and 0.1 level, respectively).

\begin{tabular}{|c|c|c|c|}
\hline Heavy Metal & Spectral Parameters & Combinations of Spectral Variables & $\mathbf{r}$ \\
\hline \multirow{6}{*}{$\mathrm{Cd}$} & Raw Reflectance (R) & $\mathrm{R}_{1089.379}{ }^{*} \mathrm{R}_{2222.424}$ & $0.36^{* *}$ \\
\hline & First Derivative (FD) & $\mathrm{FD}_{938.753}{ }^{*} \mathrm{FD}_{795.231}$ & $0.60 * *$ \\
\hline & Second Derivative (SD) & $\mathrm{SD}_{346.839} * \mathrm{SD}_{808.196}$ & $-0.54^{* *}$ \\
\hline & Logarithm of Reciprocal (LG) & $\mathrm{LG}_{784.504} / \mathrm{LG}_{492.442}$ & $0.42 * *$ \\
\hline & Reciprocal Transformation (RT) & $\mathrm{RT}_{2253.954} / \mathrm{RT}_{2228.733}$ & $0.40 * *$ \\
\hline & Continuum Removal (CR) & $\mathrm{CR}_{348.024}-\mathrm{CR}_{2222.424}$ & $-0.48^{* *}$ \\
\hline \multirow{6}{*}{$\mathrm{Hg}$} & Raw Reflectance (R) & $\mathrm{R}_{2222.424} / \mathrm{R}_{1219.677}$ & $0.38^{* *}$ \\
\hline & First Derivative (FD) & $\mathrm{FD}_{1373.48}+7 * \mathrm{FD}_{430.21}$ & $0.58^{* *}$ \\
\hline & Second Derivative (SD) & $30 * \mathrm{SD}_{356.912}-25 * \mathrm{SD}_{348.024}$ & $-0.43^{* *}$ \\
\hline & Logarithm of Reciprocal (LG) & $\mathrm{LG}_{2222.424}-\mathrm{LG}_{1212.22}$ & $-0.47^{* *}$ \\
\hline & Reciprocal Transformation (RT) & $7 * \mathrm{RT}_{2222.424}-12 * \mathrm{RT}_{1212.22}$ & $-0.42 * *$ \\
\hline & Continuum Removal (CR) & $\mathrm{CR}_{2486.193}-\mathrm{CR}_{350.987}$ & $-0.48^{* *}$ \\
\hline \multirow{6}{*}{ As } & Raw Reflectance (R) & $\mathrm{R}_{347.431}+\mathrm{R}_{1765.023}$ & $-0.36^{* *}$ \\
\hline & First Derivative (FD) & $\mathrm{FD}_{2342.058} / \mathrm{FD}_{966.869}$ & $-0.60 * *$ \\
\hline & Second Derivative (SD) & $6 * \mathrm{SD}_{363.425}-5 * \mathrm{SD}_{340.316}$ & $-0.49 * *$ \\
\hline & Logarithm of Reciprocal (LG) & $\mathrm{LG}_{345.653}-\mathrm{LG}_{344.467}$ & $-0.40^{* *}$ \\
\hline & Reciprocal Transformation (RT) & $\mathrm{RT}_{343.291} / \mathrm{RT}_{343.874}$ & $-0.49 * *$ \\
\hline & Continuum Removal (CR) & $\mathrm{CR}_{344.467}-\mathrm{CR}_{2473.69}$ & $-0.54^{* *}$ \\
\hline
\end{tabular}

Table 3. The combined spectral variables selected and corresponding criteria.

\begin{tabular}{ccccccc}
\hline $\begin{array}{c}\text { Heavy } \\
\text { Metal }\end{array}$ & $\begin{array}{c}\text { Combined Spectral } \\
\text { Variables }\end{array}$ & Adjusted $\mathbf{R}^{2}$ & $\begin{array}{c}\text { Estimation } \\
\text { Error }\end{array}$ & F & $\begin{array}{c}\text { Significance } \\
\text { Level }\end{array}$ & $\begin{array}{c}\text { Variance } \\
\text { Inflation Factor }\end{array}$ \\
\hline $\mathrm{Cd}$ & $\begin{array}{c}\mathrm{FD}_{938.753}{ }^{*} \mathrm{FD}_{795.231} \\
\mathrm{LG}_{784.504} / \mathrm{LG}_{492.442} \\
\mathrm{FD}_{1373.48}+7^{*} \mathrm{FD}_{430.21},\end{array}$ & 0.226 & 0.343 & 15.413 & 0.000 & 4.045 \\
$\mathrm{Hg}$ & $\begin{array}{c}\mathrm{LG}_{2222.424}-\mathrm{LG}_{1212.22}, \\
7 * \mathrm{RT}_{2222.424}-12^{*} \mathrm{RT}_{1212.22} \\
\mathrm{FD}_{2342.058} / \mathrm{FD}_{966.869} \\
\mathrm{RT}_{343.281} / \mathrm{RT}_{343.874} \\
6^{*} \mathrm{SD}_{363.425}-5^{*} \mathrm{SD}_{340.316}\end{array}$ & 0.300 & 0.235 & 7.781 & 0.000 & 6.324 \\
$\mathrm{As}$ & & & & & 5.006 \\
\hline
\end{tabular}

\subsection{Estimation and Accuracy Validation of Soil Heavy Metal Contents for Soil Sample Points}

Both BPNN and PSO-BPNN method were used and compared to estimate the contents of the soil heavy metal: $\mathrm{Cd}, \mathrm{Hg}$, and As. For both methods, the input layer in the neural network was composed of two nodes for $\mathrm{Cd}$ and three nodes for $\mathrm{Hg}$ and As. The output layer consisted of the soil heavy metal contents. The two nodes were used in the hidden layer to train the networks. For both BPNN and PSO-BPNN, 50 training samples were randomly selected to train the response relationships 
between the soil heavy metal contents and the optimal spectral variables (Figure 6). For both Cd and $\mathrm{Hg}$, obviously, BPNN led to over-estimations for the smaller values and under-estimations for the larger values, and the PSO-BPNN greatly mitigated the over-estimations and underestimations. For As, BPNN resulted in under-estimations for some of the smaller values and overestimation for the largest value, and the PSO-BPNN created reverse results with smaller biases. This implied that overall, PSO-BPNN improved the modeling of the soil heavy metal contents.

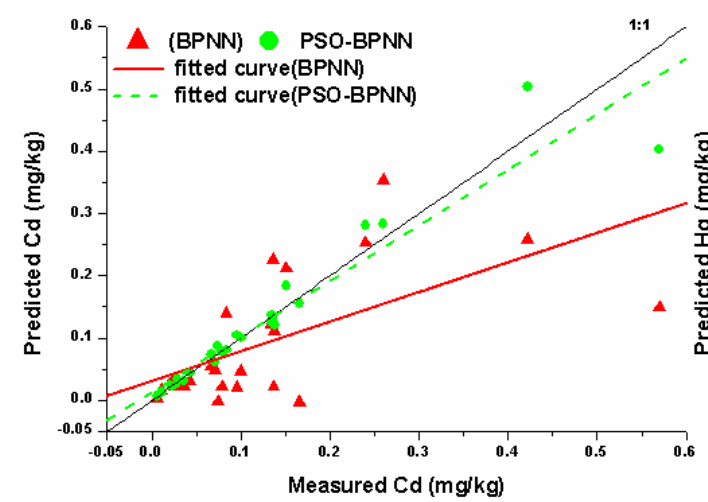

(a) soil heavy metal $\mathrm{Cd}$

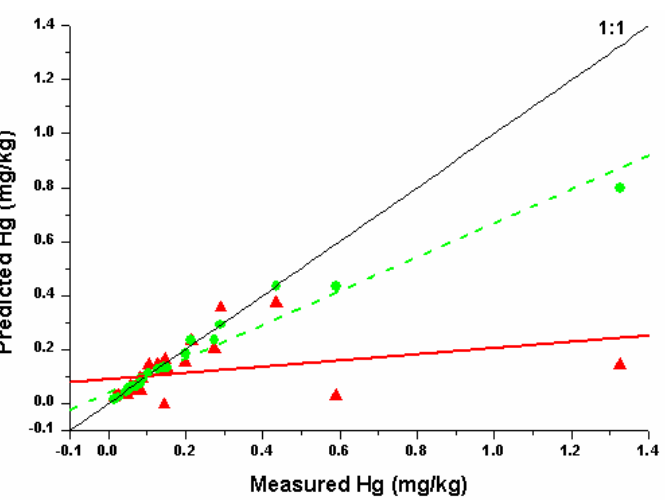

(b) soil heavy metal $\mathrm{Hg}$

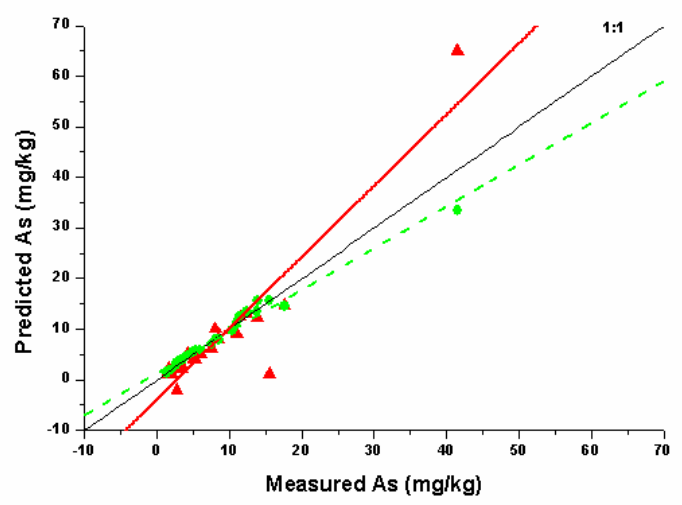

(c) soil heavy metal As

Figure 6. The scatter plots of the predicted versus measured heavy metal contents ( $\mathrm{Cd}, \mathrm{Hg}$, and $\mathrm{As}$ ) using the training dataset and both BPNN and PSO-BPNN method. (a) Soil heavy metal Cd; (b) Soil heavy metal $\mathrm{Hg}$; (c) Soil heavy metal As.

In order to validate the estimation accuracy of both methods for the soil heavy metal contents, 25 test samples were used to create the predictions of the soil heavy metal contents (Figure 7). Most of the scattered points for the estimated contents of all the soil heavy metals versus the measured values were distributed around the 1:1 line. For Cd and $\mathrm{Hg}$, however, BPNN led to over-estimations for the smaller values and under-estimations for the larger values. The PSO-BPNN reduced the over-estimations and under-estimations of $\mathrm{Cd}$ content. For $\mathrm{Hg}$, although the under-estimation by PSO-BPNN for the largest value was more obvious than by BPNN, overall the estimates from PSO-BPNN were closer to the line of 1:1 than those from BPNN. Moreover, the predicted contents of As from BPNN and PSO-BPNN had a similar trend, but the scatter points of the predictions from PSO-BPNN were closer to the line of 1:1 than those from BPNN. 


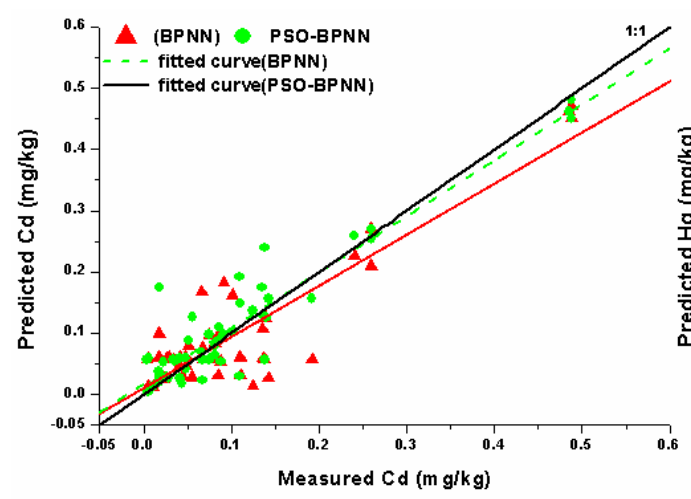

(a) soil heavy metal $\mathrm{Cd}$

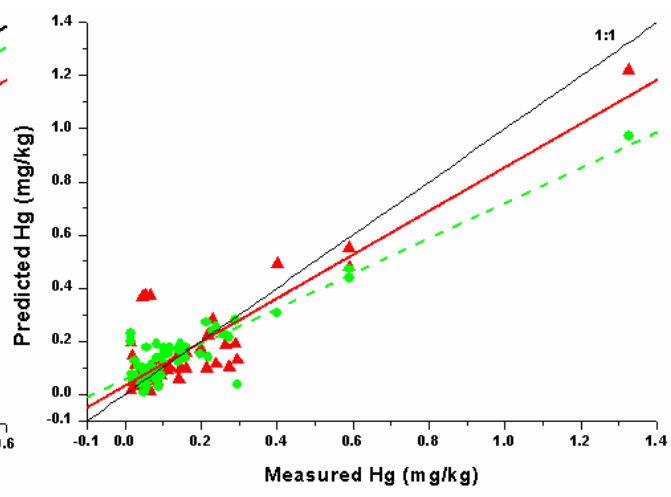

(b) soil heavy metal $\mathrm{Hg}$

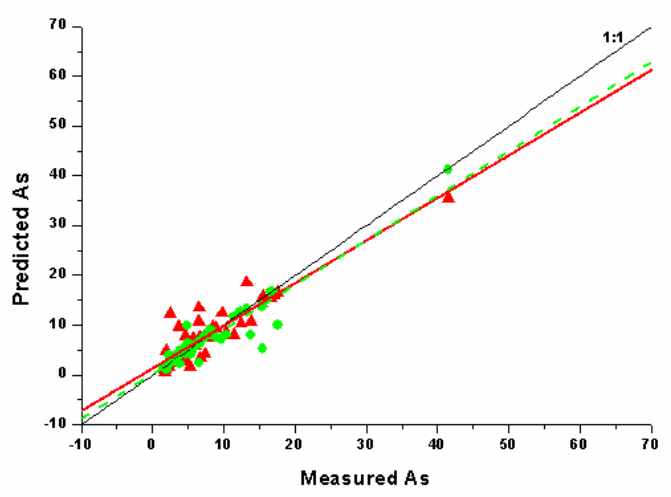

(c) soil heavy metal As

Figure 7. The scatter plots of the predicted values against the measured contents of $\mathrm{Cd}, \mathrm{Hg}$, and As. (a) Soil heavy metal Cd; (b) Soil heavy metal $\mathrm{Hg}$; (c) Soil heavy metal As.

The predicted contents of the soil heavy metals, from BPNN and PSO-BPNN, were further compared with the field observations from 25 test samples by calculating the coefficient of determination $\left(\mathrm{R}^{2}\right)$, the mean relative error (MRE), and the relative RMSE (RRMSE) in Table 4. The estimates from PSO-BPNN were more accurate than those from BPNN. Compared with BPNN, PSO-BPNN decreased the MRE by $68 \%$ to $71 \%$ and the RRMSE by $64 \%$ to $67 \%$. For all three soil heavy metal contents, PSO-BPNN also significantly increased the coefficients of determination. The improvements were thus statistically very significant.

Table 4. The estimation accuracies of soil heavy metal contents using BPNN and PSO-BPNN methods based on the test dataset.

\begin{tabular}{ccccccc}
\hline & \multicolumn{2}{c}{ BPNN } & \multicolumn{3}{c}{ PSO-BPNN } \\
\hline $\begin{array}{c}\text { Heavy } \\
\text { Metal }\end{array}$ & $\mathbf{R}^{\mathbf{2}}$ & $\begin{array}{c}\text { Mean Relative Error (MRE) } \\
\mathbf{( \% )}\end{array}$ & $\begin{array}{c}\text { RRMSE } \\
\mathbf{( \% )}\end{array}$ & $\mathbf{R}^{\mathbf{2}}$ & $\begin{array}{c}\text { MRE } \\
\mathbf{( \% )}\end{array}$ & $\begin{array}{c}\text { RRMSE } \\
\mathbf{( \% )}\end{array}$ \\
\hline $\mathrm{Cd}$ & 0.390 & 34.053 & 36.217 & 0.755 & 10.074 & 12.037 \\
$\mathrm{Hg}$ & 0.283 & 37.784 & 38.514 & 0.742 & 10.909 & 13.862 \\
$\mathrm{As}$ & 0.516 & 29.955 & 30.970 & 0.811 & 9.594 & 11.121 \\
\hline
\end{tabular}

\subsection{Estimation and Accuracy Validation of Soil Heavy Metal Contents at the Regional Scale}

In this study, only the PSO-BPNN method was used to map the spatial patterns of soil heavy metal Cd content. To obtain consistent bands of HJ-1A HSI image, the filed measured spectral data were spectrally re-sampled by stepwise merging adjacent bands. The re-sampled bands were then selected to yield the optimal spectral variables. Finally, four bands, including B114: $942.705 \mathrm{~nm}$, B94: $795.065 \mathrm{~nm}$, B16: $493.590 \mathrm{~nm}$ and B92: $782.805 \mathrm{~nm}$, were selected to construct the HSI-based PSO-BPNN model to map the content of soil heavy metal Cd (Figure 8). 
$113^{\circ} 20^{\prime} 0^{\prime \prime E} \quad 113^{\circ} 24^{\prime} 0^{\prime \prime E} \quad 113^{\circ} 28^{\prime} 0^{\prime \prime E} \quad 113^{\circ} 32^{\prime} 0^{\prime \prime E} \quad 113^{\circ} 36^{\prime} 0^{\prime \prime E}$

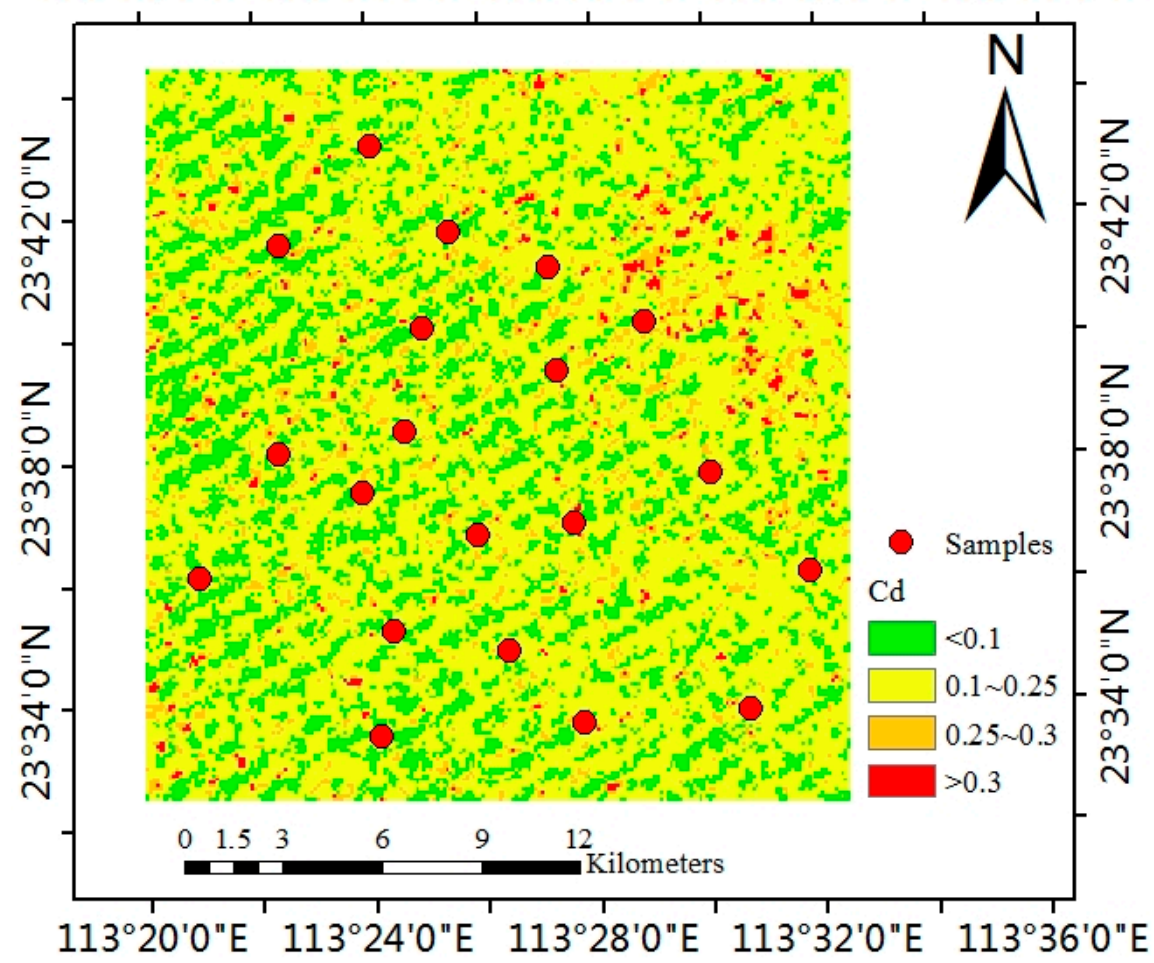

Figure 8. The spatial distribution of soil heavy metal $\mathrm{Cd}$ content and sampling points.

In order to validate the feasibility of PSO-BPNN to estimate the content of soil heavy metal Cd at the regional scale, the values of the field measured $\mathrm{Cd}$ content were compared with its estimates (Table 5). The HSI-based PSO-BPNN model explained $65.6 \%$ of the variance in Cd content with an RRMSE of $35.989 \%$. The mean value of the measured contents of Cd was close to the average value of the estimates. Their difference was no significantly different from zero, indicating that PSO-BPNN was capable of estimating $\mathrm{Cd}$ content at the regional scale.

Table 5. Comparison between the measured and estimated values for soil heavy metal Cd content $\left(\mathrm{mg}^{\mathrm{kg}} \mathrm{kg}^{-1}\right)$.

\begin{tabular}{ccccccc}
\hline Category & Maximum & Minimum & Mean & Standard Deviation & $\mathbf{R}^{\mathbf{2}}$ & RRMSE (\%) \\
\hline Measured value & 0.218 & 0.068 & 0.137 & 0.044 & \multirow{2}{*}{0.656} & 35.989 \\
Estimated value & 0.249 & 0.032 & 0.122 & 0.053 & & \\
\hline
\end{tabular}

\section{Discussion}

Soil heavy metals, such as $\mathrm{Cd}, \mathrm{Hg}$, and As contaminate soils and thus endanger human life and deteriorate the environment. Accurately estimating and mapping the contents of the soil heavy metals and monitoring their dynamics become critical. Hyper-spectral data provide the potential data for monitoring scale-regional soil heavy metal contents, by developing and using the relationship of hyperspectral bands and various transformations with the soil heavy metals. However, the availability of a large number of hyperspectral bands leads to the difficulty of selecting the spectral variables that have significant contributions in improving the estimation of soil heavy metal contents [3-5]. Traditionally, a correlation analysis of hyperspectral data with soil heavy metal contents has been widely used $[26,27]$. But, the correlation analysis ignores collinearity and duplication of information among the hyperspectral bands, which often results in low estimation accuracy. In this study, we integrated the correlation analysis and VIF analysis for the selection of the hyperspectral data collected in the field, their transformations (FD, SD, LG, RT, etc.), and the combinations of the transformations by addition, 
subtraction, multiplication, and division. This process did not only lead to the spectral variables that had highest correlations with the contents of the soil heavy metals, but also eliminated the spectral variables that were highly correlated with each other and had information duplication. It was found that compared with the original hyperspectral bands and their transformations, the combined spectral variables greatly improved the correlations with the contents of the soil heavy metals. This indicated that the relationships of the soil heavy metal contents with the spectral variables are complicated and could not be well-explained by the simple hyperspectral bands and their transformations. This finding was supported by the studies of Kemper and Sommer (2002) [8] and Wu et al. (2005) [19].

Another big challenge of using hyperspectral data to map the contents of the soil heavy metals for a large area was the development of spatial interpolation algorithms that can be used to account for the relationships of the selected spectral variables with the contents of the soil heavy metals [6-10]. Previous studies $[11,12,28]$ demonstrated that the BPNN method was a good alternative. However, the large uncertainties of the input initial parameters affected the improvement of estimation accuracy for the contents of the soil heavy metals [29]. In this study, the PSO algorithm was introduced to BPNN, which led to an integrated PSO-BPNN method to optimize the initial parameter values. The research results showed that the PSO-BPNN method significantly increased the estimation accuracies of the soil heavy metal contents by greatly decreasing the MRE and RRMSE values. The superiority of PSO-BPNN was attributed to the optimization of the initial input parameters (thresholds and weights) for BPNN by the PSO algorithm, which resulted in the solution for the problem of being stuck in the local minima $[8,30]$. This implies that PSO-BPNN is very promising in improving the estimation and mapping of the soil heavy metal contents using hyperspectral imagery.

In order to validate the regional-scale applicability of PSO-BPNN, the HJ-1A data were used to map the soil heavy metal $\mathrm{Cd}$ content. The results of validation using the test sample data showed that the selected spectral variables explained $65.6 \%$ of the variance in Cd content and led to an RRMSE of $36 \%$ for mapping Cd content. This indicated that PSO-BPNN had great potential to map the soil heavy metal $\mathrm{Cd}$ content at a large scale. However, compared with that using the hyperspectral data collected in the field, the estimation accuracy of the soil heavy metal Cd using the HJ-1A image was lower. The reason might be mainly due to the effect of vegetation canopies in the HJ-1A image and its coarser spectral resolution [31]. Thus, in order to eliminate the vegetation canopy effect, the extraction and consideration of soil component using a spectral unmixing technique should be a focus of future research.

On the other hand, most of the soil sample data, used to train BPNN and PSO-BPNN, had low contents of the soil heavy metals. This led to larger errors for the test samples that had high heavy metal contents and affected performance and prediction accuracy [32]. Thus, in order to improve the prediction accuracy of the soil heavy metal contents, more soil samples with high values of the contents have to be collected to improve the performance of PSO-BPNN in the future.

Finally, in this study only the soil heavy metal Cd content was mapped by PSO-BPNN, due to the limitation of the HJ-1A HSI data with $450 \mathrm{~nm}-960 \mathrm{~nm}$. Future research that would map the contents of $\mathrm{Hg}$ and As, using satellite hyperspectral images, may be followed through the Chinese hyperspectral satellite Gaofen-5 data, which covers a wider spectral region of $400 \mathrm{~nm}-2500 \mathrm{~nm}$.

\section{Conclusions}

In this study, the integrated PSO-BPNN method was developed and used to improve the estimation accuracy of the soil heavy metal $(\mathrm{Cd}, \mathrm{Hg}$, and As) contents in the soil samples collected in Guangdong, which is one of the most developed provinces in China. The following conclusions could be drawn: (1) Based on the sample averages, overall the contents of the soil heavy metals did not exceed the normative heavy metal contents, but the sample maximum values were higher than the corresponding environment baseline values; (2) the combined spectral variables had a stronger capacity of explaining variances of the soil heavy metals than the original spectral data and transformed spectral variables; (3) compared with BPNN, PSO-BPNN significantly increased the estimation accuracy of the soil heavy 
metal contents by decreasing the MRE and RRMSE by $68 \%$ to $71 \%$ and $64 \%$ to $67 \%$, respectively; and (4) PSO-BPNN, coupled with a HJ-1A hyperspectral image also led to an acceptable accuracy of mapping the $\mathrm{Cd}$ content at a regional scale. This indicated that PSO-BPNN provided great potential to accurately estimate the soil heavy metal contents.

Author Contributions: Z.L. and P.L. conceived and designed the experiments; P.L. analyzed the data, created the tables and figures, and finished the first version of the paper; Z.L., Y.H., Z.S., Y.P. and L.W. contributed valuable opinions during the manuscript writing; G.W. revised the whole manuscript. All authors read and approved the final manuscript.

Funding: This research was supported by the National Key Research and Development Program of China ("Source Identification and Contamination Characteristics of Heavy Metals in Agricultural Land and Products", 2016YFD0800301), the Guangdong Provincial Science and Technology Project of China (2017A050501031), and the Guangzhou Science and Technology Project, China (201804020034).

Conflicts of Interest: The authors declare no conflict of interest.

\section{References}

1. Mouazen, A.; Maleki, M.; De Baerdemaeker, J.; Ramon, H. On-line measurement of some selected soil properties using a VIS-NIR sensor. Soil Tillage Res. 2007, 93, 13-27. [CrossRef]

2. Jarmer, T.; Vohland, M.; Lilienthal, H.; Schnug, E. Estimation of some chemical properties of an agricultural soil by spectroradiometric measurements. Pedosphere 2008, 18, 163-170. [CrossRef]

3. Tan, K.; Ye, Y.; Cao, Q.; Du, P.; Dong, J. Estimation of arsenic contamination in reclaimed agricultural soils using reflectance spectroscopy and ANFIS method. IEEE J.-STARS 2014, 7, 2540-2546.

4. Wu, D.W.; Wu, Y.Z.; Ma, H.R. Study on the prediction of soil heavy metal elements content based on Mid-Infrared diffuse reflectance spectra. Spectrosc. Spectr. Anal. 2009, $29,114$.

5. Kooistra, L.; Wanders, J.; Epema, G.; Leuven, R.; Wehrens, R.; Buydens, L. The potential of field spectroscopy for the assessment of sediment properties in river floodplains. Anal. Chim. Acta 2003, 484, 189-200. [CrossRef]

6. Lian, S.; Jian, J.; Tan, D.J.; Xie, H.B.; Luo, Z.F.; Gao, B. Estimate of heavy metals in soil and streams using combined geochemistry and field spectroscopy in Wansheng mining area, Chongqing, China. Int. J. Appl. Earth. Obs. 2015, 34, 1-9.

7. Lu, P.; Wang, L.; Niu, Z.; Li, L.; Zhang, W. Prediction of soil properties using laboratory VIS-NIR spectroscopy and Hyperion imagery. J. Geochem. Explor. 2013, 132, 26-33. [CrossRef]

8. Kemper, T.; Sommer, S. Estimate of heavy metal contamination in soil after a mining accident using reflectance spectroscopy. Environ. Sci. Technol. 2002, 36, 2742-2747. [CrossRef] [PubMed]

9. He, J.L.; Jiang, J.J.; Zhou, S.L.; Xu, J.; Cai, H.L.; Zhang, C.Y. The hyperspectral characteristics and retrieval of soil organic matter content. Sci. Agric. Sin. 2007, 40, 638-643.

10. Zhang, Q.X.; Zhang, H.B.; Liu, W.K.; Zhao, S.X. Inversion of heavy metals content with hyperspectral reflectance in soil of well-facilitied capital farmland construction areas. Trans. Chin. Soc. Agric. Eng. 2017, 33, 230-239.

11. Ghadimi, F. Prediction of heavy metals contamination in the groundwater of Arak region using artificial neural network and multiple linear regression. J. Tethys. 2015, 3, 203-215.

12. Gandhimathi, A.; Meenambal, T. Spatial prediction of heavy metal pollution for soils in Coimbatore, India based on ANN and kriging method. Eur. Sci. J. 2012, 8, 1857.

13. Guo, Y.K.; Liu, L.; Liu, N.; Zhu, S.T.; Li, D. The prediction of the heavy metal Fe content in rice field based on support vector machine regression. Beijing Surv. Map. 2017, 6, 10-13.

14. Guo, Z.X.; Wang, J.; Chai, M.; Chen, Z.P.; Zhan, Z.S.; Zheng, W.P.; Wei, X.G. Spatiotemporal variation of soil pH in Guangdong Province of China in past 30 years. Chin. J. Appl. Ecol. 2011, 22, 425-430.

15. Chang, C.W.; Laird, D.A.; Mausbach, M.J.; Hurburgh, C.R., Jr. Near-infrared reflectance spectroscopy-principal components regression analyses of soil properties. Soil Sci. Soc. Am. J. 2001, 65, 480-490. [CrossRef]

16. Kooistra, L.; Wehrens, R.; Leuven, R.; Buydens, L. Possibilities of visible-near-infrared spectroscopy for the assessment of soil contamination in river floodplains. Anal. Chim. Acta 2001, 446, 97-105. [CrossRef]

17. Wang, J.J.; Cui, L.J.; Gao, W.X.; Shi, T.Z.; Chen, Y.; Gao, Y. Prediction of low heavy metal concentrations in agricultural soils using visible and near-infrared reflectance spectroscopy. Geoderma 2014, 216, 1-9. [CrossRef] 
18. Gomez, C.; Lagacherie, P.; Coulouma, G. Continuum removal versus PLSR method for clay and calcium carbonate content estimation from laboratory and airborne hyperspectral measurements. Geoderma 2008, 148, 141-148. [CrossRef]

19. Wu, Y.; Chen, J.; Wu, X.; Tian, Q.; Ji, J.; Qin, Z. Possibilities of reflectance spectroscopy for the assessment of contaminant elements in suburban soils. Appl. Geochem. 2005, 20, 1051-1059. [CrossRef]

20. Tian, H.J.; Cao, C.X.; Xu, M.; Zhu, Z.C.; Liu, D.; Liu, D.; Wang, X.Q.; Cui, S.H. Estimation of chlorophyll-a concentration in coastal waters with HJ-1A HSI data using a three-band bio-optical model and validation. Int. J. Remote Sens. 2014, 35, 5984-6003. [CrossRef]

21. Anne, N.J.P.; Abd-Elrahman, A.H.; Lewis, D.B.; Hewitt, N.A. Modeling soil parameters using hyperspectral image reflectance in subtropical coastal wetlands. Int. J. Appl. Earth Obs. Geoinform. 2014, 33, 47-56. [CrossRef]

22. Gómez, R.S.; Pérez, J.G.; Martín, M.D.L.; García, C.G. Collinearity diagnostic applied in ridge estimation through the variance inflation factor. J. Appl. Stat. 2016, 43, 19.

23. Wu, J.H.; Wang, G.L.; Wang, J.; Su, Y. BP neural network and multiple linear regression in acute hospitalization costs in the comparative study. J. Fluid Mech. 2011, 5, 50-51. [CrossRef]

24. Yu, X.; Efe, M.O.; Kaynak, O. A general backpropagation algorithm for feedforward neural network learning. IEEE Trans. Neural Netw. 2002, 13, 251-254. [PubMed]

25. Kennedy, J.; Eberhart, R. Particle Swarm Optimization. In Proceedings of the Fourth IEEE International Conference on Neural Networks, Perth, Australia, 27 November-1 December 1995; Volume 4, pp. 1942-1948.

26. Singh, A.N. Estimation of as and cu contamination in agricultural soils around a mining area by reflectance spectroscopy: A case study. Pedosphere 2009, 9, 719-726.

27. Liu, M.; Liu, X.; Li, M.; Fang, M.; Chi, W. Neural-network model for estimating leaf chlorophyll concentration in rice under stress from heavy metals using four spectral indices. Biosyst. Eng. 2010, 106, 223-233. [CrossRef]

28. Pandit, C.; Filippelli, G.; Lin, L. Estimation of heavy-metal contamination in soil using reflectance spectroscopy and partial least-squares regression. Int. J. Remote Sens. 2010, 31, 13. [CrossRef]

29. Wang, F.; Gao, J.; Zha, Y. Hyperspectral sensing of heavy metals in soil and vegetation: Feasibility and challenges. ISPRS J. Photogramm. Remote Sens. 2018, 136, 73-84. [CrossRef]

30. Khosravi, V.; Ardejani, F.D.; Yousefi, S.; Aryafar, A. Monitoring soil lead and zinc contents via combination of spectroscopy with extreme learning machine and other data mining methods. Geofis. Int. 2018, 318, $29-41$. [CrossRef]

31. Luo, H.; Zheng, Y. The comparison of citrus canopy spectral characteristics obtained by the HJ-1A/ HSI and ASD field spectrometer. In Proceedings of the 9th IEEE International Conference on Fuzzy Systems and Knowledge Discovery, Sichuan, China, 29-31 May 2012; pp. 650-655.

32. Sadr, M.H.; Astaraki, S.; Salehi, S. Improving the neural network method for finite element model updating using homogenous distribution of design points. Arch. Appl. Mech. 2007, 77, 795-807. [CrossRef] 